\title{
Fulminating encephalopathy associated with Shigella flexneri infection
}

\author{
R SANDYK AND M J W BRENNAN \\ Department of Medicine, Hillbrow Hospital, Johannesburg, South Africa
}

\begin{abstract}
SUMMARY Three cases of rapidly fatal encephalopathy associated with Shigella flexneri infection are reported. There was a lack of severe intestinal involvement and absence of metabolic derangement. In all 3 patients, areas of necrosis were present throughout the brains; and in one case pontine haemorrhages and demyelination were seen. This report supports the evidence of a particular neurotoxic effect in shigellosis.
\end{abstract}

Shigellosis is an acute inflammatory disease of the colon produced by bacteria of the genus Shigella $\mathrm{sp}$. and characterised by fever, crampy abdominal pain, and frequent loose stools which may contain mucus, pus, or blood. The disease caused by $S$. flexneri is generally benign. Central nervous system complications-such as febrile convulsions-occur in about $30 \%$ of patients and may be a reaction to the fever itself, or a manifestation of an acute encephalopathy produced by a neurotoxin elaborated by Shigella sp. ${ }^{12}$ Here we describe 3 cases in whom infection with $S$. flexneri was associated with a fulminating and rapidly fatal encephalopathy.

\section{Case reports}

Case 1. An 11-year-old boy was admitted to hospital at 0400 hours in a comatose state. He had woken his parents at 0300 hours complaining of abdominal pain and had vomited 3 times. Examination showed blood pressure of $100 / 60 \mathrm{mmHg}$, pulse rate $95 / \mathrm{min}$ and regular, rectal temperature $37^{\circ} \mathrm{C}$, and respiratory rate $12 /$ min with a Cheyne-Stokes pattern. The left pupil was 6 and the right $5 \mathrm{~mm}$ in diameter; both were unresponsive to light. There was no papilloedema and no response to caloric or oculovestibular testing. The limbs were flaccid and all reflexes absent. A tip of spleen was palpable and there was a petechial rash on the skin and mucous membranes. S. flexneri was subsequently isolated from the stool. Laboratory data were: erythrocyte sedimention rate $18 \mathrm{~mm}$ in the 1st hour (Westergren); haemoglobin $13.9 \mathrm{~g} / \mathrm{dl}$; leucocyte count $14.0 \times 10^{9} / 1$ with normal differential; serum electrolytes and serum enzyme values were normal with the exception of a raised alkaline phosphatase level (189 U/l). The urine showed presence of blood and protein. Lumbar puncture fluid was under slightly raised pressure $\left(200 \mathrm{mmH}_{2} \mathrm{O}\right)$; cerebrospinal fluid analysis was normal. An electrocardiogram showed a pattern of acute pericarditis $\vec{A}$ (not confirmed at necropsy). Electroencephalogram showed extremely low voltage activity approaching $\vec{\omega}$ an isoelectric state. Computerised tomography of the brain showed patchy areas of low density, particularly in the temporal lobes. Necropsy showed marked congestion and oedema of the brain, of the small and 9 large bowel, and of the liver, spleen, kidneys, and $\overrightarrow{-}$ lungs. The colonic mucosa was congested with a $\partial$ polymorphonuclear cell infiltrate and a fibro- 을 suppurative exudate containing polymorphonuclear cells covering the mucosal surface. In the brain were $c$ found petechial haemorrhages in the pons, patchy areas of necrosis in the grey and white matter associated with occlusion of small vessels, and areas of perivascular demyelination in the hemispheric $\underset{\infty}{\infty}$ white matter.

Case 2. A 9-year-old girl was admitted to hospital with a 12-hour history of mild headache, fever, abdominal pains, and the passage of frequent, yellow, loose stools containing neither mucus nor blood. On $\mathbb{D}$ examination she was pyrexial $\left(38.5^{\circ} \mathrm{C}\right)$ with blood $\overrightarrow{\vec{A}}$ pressure $110 / 60 \mathrm{mmHg}$ and pulse rate $110 / \mathrm{min}$ and $\frac{O}{3}$ regular. The stools were at this time loose, yellow, and contained small amounts of blood and mucus. Stool culture subsequently yielded $S$. flexneri type $2 \mathrm{a}$. Laboratory investigations gave normal results. Treatment was started with chloramphenicol $500 \mathrm{mg}$ : every 8 hours given orally. Fifteen hours after admission, spontaneous respiration ceased and she $\delta$ failed to respond to noxious stimulation. Pupils were $₹$ equal (6 $\mathrm{mm}$ in diameter) and unresponsive to light; 우 there was no papilloedema. Reflexes were absent throughout the body and the limbs were flaccid. An $?$ electroencephalogram performed the next day was isoelectric. Necropsy showed extensive areas of $\tilde{\sigma}$ liquefactive necrosis throughout the brain. The rest $N$ of the organs were normal apart from the large N bowel, the mucosa of which was infiltrated by polymorphonuclear cells.

Case 3. An 11-year-old girl was admitted to hospital with a history of sudden onset of headache and fever. + Two hours before admission she had vomited $4{ }^{-}$ times and had passed several loose, yellow stools $\vec{D}$ without blood or mucus. On examination she was $\frac{?}{1}$ drowsy and pyrexial $\left(38^{\circ} \mathrm{C}\right)$ with blood pressure $\varrho$ 
$110 / 60 \mathrm{mmHg}$ and pulse rate $130 / \mathrm{min}$ and regular. Results of laboratory investigations were normal. $S$. flexneri type 2a was later isolated from the stool. Treatment was started with ampicillin $250 \mathrm{mg}$ every 8 hours orally. Six hours after admission she had a grand mal seizure and shortly thereafter became apnoeic and unresponsive to noxious stimulation. The pupils were widely dilated $(6 \mathrm{~mm})$ and fixed, and there was no response to caloric or oculovestibular testing. Cerebrospinal fluid analysis was normal. Computerised tomography scan of the brain showed diffuse areas of low density throughout the brain. Five hours later the electroencephalogram was isoelectric. At necropsy the entire bowel was congested and the colonic mucosa was infiltrated by polymorphonuclear cells. Extensive necrosis was present throughout the brain and coning of the cerebellum was noted. The remainder of the organs seemed normal.

\section{Discussion}

Neurological complications of Shigella sp. infections are rare and consist of febrile convulsions in children and peripheral neuropathy in adults. ${ }^{3}$ Notable in the cases reported here were the lack of severe intestinal involvement and absence of metabolic derangement, and the fulminating nature of the encephalopathy. These facts suggest a toxic aetiology. $S$. flexneri type 2a may produce an exotoxin similar to that of $S$. dysenteriae type 1 . The toxin produced by the latter is a protein with a molecular weight of 50000 ; it is also a potent enterotoxin. It has the properties of a neurotoxin (being paralytic and lethal for rabbit and mouse) and cytotoxic (lethal for cell culture) in addition to causing intestinal fluid secretion. ${ }^{3}$ Although the exact role of this substance in the pathogenicity of shigellae remains undefined, we suggest that such a toxin, either elaborated in the gut or ingested preformed, was responsible for the rapidly fatal picture described in these 3 patients. The precise mechanism of action on the nervous system is unknown, since no specific disease was revealed in the brains at necropsy. In all 3 patients, areas of necrosis were present throughout the brains; only in Case 1 were pontine haemorrhages and demyelination seen. Haemorrhages may be explicable on the basis of raised intracranial pressure before death, while the demyelination may reflect an action of the toxin or be an incidental finding. This report supports the evidence of a particular neurotoxic effect in shigellosis.

\section{References}

1 Kowlessar M, Forbes G B. The febrile convulsion in shigellosis. N Engl J Med 1966; 258: 520-6.

2 Donald W D, Winkler C H, Jr, Bargeron L M, Jr. The occurrence of convulsions in children with shigella gastroenteritis. J Pediatr 1956; 48: 323-7.

3 Smith D H. Shigellosis (bacillary dysentery). In: Vaughan V C, McKay R, Jr, Behrman R E, eds. Nelson textbook of pediatrics, eleventh edition. Philadelphia: Saunders, 1979: 782-6.

Correspondence to $\operatorname{Dr} R$ Sandyk, University of the Witwatersrand, Medical School, Hospital Street, Johannesburg 2001, South Africa.

Received 11 September 1982

\section{Influence of breast feeding on the clinical features of salt-losing congenital adrenal hyperplasia}

\section{JOSEPH A CURTIS AND JOHN D BAILEY}

Division of Endocrinology, Department of Pediatrics, Hospital for Sick Children, Toronto, Canada

SUMMARY Feeding habits before diagnosis were reviewed in 32 infants with salt-losing congenital adrenal hyperplasia who were admitted to hospital in adrenal crisis. Most breast-fed babies failed to thrive, seldom vomited, and despite severe salt wasting, presented at a later age than their formulafed counterparts.

Salt-losing congenital adrenal hyperplasia (SL-CAH) is a genetically inherited enzyme deficiency, the most commonly affected enzyme being 21-hydroxylase. ${ }^{1}$
Clinically, SL-CAH is characterised by a nonspecific failure to thrive in the first few days of life that progresses to acute addisonian crisis with anorexia, vomiting, dehydration, dystrophy, diarrhoea, and circulatory insufficiency in the 2nd week. ${ }^{2}$

Although the initial crisis occurs in most infants with SL-CAH in the 2nd or 3rd weeks of life, it can occur as early as the first week or as late as several months. Kowarski ${ }^{3}$ suggests that the age at which the infant presents depends on the severity of the case, which in turn is related to the degree of sodium 